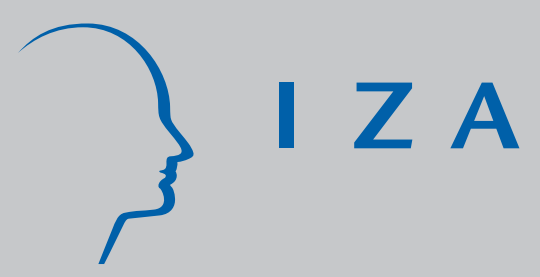

IZA DP No. 3246

Stability and Dynamics in an Overlapping Generations Economy with Flexible Wage Negotiations

Erkki Koskela

Mikko Puhakka

December 2007 


\title{
Stability and Dynamics in an Overlapping Generations Economy with Flexible Wage Negotiations
}

\author{
Erkki Koskela \\ University of Helsinki \\ and IZA \\ Mikko Puhakka \\ University of Oulu
}

Discussion Paper No. 3246

December 2007

\author{
IZA \\ P.O. Box 7240 \\ 53072 Bonn \\ Germany \\ Phone: +49-228-3894-0 \\ Fax: +49-228-3894-180 \\ E-mail: iza@iza.org
}

\begin{abstract}
Any opinions expressed here are those of the author(s) and not those of the institute. Research disseminated by IZA may include views on policy, but the institute itself takes no institutional policy positions.

The Institute for the Study of Labor (IZA) in Bonn is a local and virtual international research center and a place of communication between science, politics and business. IZA is an independent nonprofit company supported by Deutsche Post World Net. The center is associated with the University of Bonn and offers a stimulating research environment through its research networks, research support, and visitors and doctoral programs. IZA engages in (i) original and internationally competitive research in all fields of labor economics, (ii) development of policy concepts, and (iii) dissemination of research results and concepts to the interested public.
\end{abstract}

IZA Discussion Papers often represent preliminary work and are circulated to encourage discussion. Citation of such a paper should account for its provisional character. A revised version may be available directly from the author. 


\section{ABSTRACT \\ Stability and Dynamics in an Overlapping Generations Economy with Flexible Wage Negotiations*}

We analyze the stability and dynamics of an overlapping generations model with imperfectly competitive labour markets. By focusing on the right-to-manage wage bargaining we assume that wage is negotiated after the capital stock decision. With Cobb-Douglas utility and production functions the steady state is unique and the steady state capital stock depends positively both on the trade union's bargaining power and on the wage elasticity of labour demand. That elasticity depends either on lower decreasing returns to scale and/or more intensive product market competition. Finally, we show that the steady state equilibrium is a saddle.

JEL Classification: J51, C62

Keywords: overlapping generations economy, capital accumulation, flexible wage negotiation, stability and dynamics

Corresponding author:

Erkki Koskela

Department of Economics

University of Helsinki

P.O. Box 17 (Arkadiankatu 7)

00014 Helsinki

Finland

E-mail: erkki.koskela@helsinki.fi

\footnotetext{
* We thank the Research Unit of Economic Structures and Growth (RUESG) at the University of Helsinki and the Yrjö Jahnsson Foundation for financial support. Koskela also thanks Academy of Finland (grant No. 1117698) for financial support as well as CES at the University of Munich for financial support and good hospitality as well as the University of Oulu for good hospitality.
} 


\section{Introduction}

It has been suggested that trade unions may affect the level of capital stock through their impact on wages and employment. Originally, Grout (1984) argued in a framework with efficient bargaining, where firms and trade unions bargain over the wage and employment, that the trade unions will have a negative effect on the level of investment in the absence of committed wage negotiation. Moreover, he argued that without binding contracts a stronger bargaining power of the trade union will always lower the capital stock. van der Ploeg (1987) demonstrated the similar result in the right-to-manage (RTM) case where the wage is subject to bargaining under the condition that labour demand is determined by firms after bargaining. Anderson and Devereux (1988) suggested that the presence of monopoly trade union might lead to more serious adverse welfare effects than in the frameworks, which abstract from the strategic effect of the firm's investment decision, i.e. when the firm can commit itself to a capital stock decision before wage determination. Anderson and Devereux (1991) used a monopoly trade union model to study the trade-off between the benefits of wage commitment and the costs of wage inflexibility in the design of the optimal contract length. They argued that there is a natural welfare trade-off between wage commitment and wage flexibility depending on the degree of complementarity between labour and capital and the variability of the industry price.

We use the RTM approach, and do not consider efficient bargaining, since we want to concentrate on the European features of labour market. In Western Europe it is usually the case that the level of wages is negotiated between unions and firms, but not the level of employment. We then consider explicitly the stock market, and our dynamical system includes the share price in addition to capital stock.

Devereux and Lockwood (1991) used a simple overlapping generations (OG) model with capital (Diamond 1965) and trade unions to provide a counterexample to some findings of Grout (1984) and van der Ploeg (1987). They argued in their efficient bargaining model under the assumption of zero depreciation of the capital stock that a move from a committed to a flexible wage negotiation, i.e. when wages are negotiated not before but after the capital stock decision, may increase the capital stock as a result of the rise in the trade union's bargaining power. In their 
model this occurs because higher bargaining power of trade union increases wage income and thus savings of the young generation.

De la Croix and Licandro (1995) utilized a slightly different version of an OG model in a unionized economy with perfect competition in the product market to investigate the effects of irreversibilities about technology and physical and human capital on economic growth, when there is uncertainty about productivity. By assuming full depreciation of the capital stock they showed that a rise in trade union power may induce a crowding-out of physical capital by pure profits so that the effect on capital stock in their model is ambiguous. They also briefly studied the dynamic properties of an OG economy by arguing that the presence of uncertainty and irreversibilities does not modify the dynamic properties of the economy, when technology is Cobb-Douglas. Dos Santos Ferreira and Lloyd-Braga (2002) have utilized a rather simple OG model with imperfect product markets including wage bargaining to show that endogenous growth is possible. They, however, and unlike we, use an efficient bargaining framework.

Coimbra, Lloyd-Braga and Modesto (2005) also used efficient bargaining in an OG model with the linear utility function and both the Cobb-Douglas and CES production functions with productive capital externalities to study the uniqueness of the steady state and local dynamics. They also assume that trade unions are firmspecific, i.e. one trade union per firm and show that for small capital externalities and Cobb-Douglas technology trade unions increase steady-state employment and local determinacy occurs. But with CES production function multiplicity of steady state is only possible in the presence of trade unions. Moreover, local Hopf bifurcation may occur even with small capital externalities if elasticity of substitution between capital and labour is sufficiently high. Lloyd-Braga and Modesto (2007) considered a model with trade union, heterogenous agents and productive labour externalities with efficient bargaining. Among other things they show that the influence of trade union both on indeterminacy of equilibrium and on dynamics depends crucially on the degree of substitutability between labour and capital. When the elasticity of substitution is greater (less) than one, there is indeterminacy (determinacy). Moreover, Hopf bifurcations occur when the elasticity of substitution is higher than one when trade union bargaining power crosses a critical value. 
De Palma and Seegmuller (2004) introduced a dual labour market into an OG model so that in one sector the wage comes from bargaining between firms and unions whereas the wage is competitive in other sector. They explore the conditions for indeterminacy of equilibrium both under the right-to-manage model and the efficient bargaining model with Cobb-Douglas utility and production functions. They argue that when the capital share is greater in the competitive part of the labour market indeterminacy always occurs. But when the capital share is greater in the unionized labour market, indeterminacy occurs only in the efficient bargaining model when the trade union's bargaining power is high enough.

It is important to point out that in most of these papers, except Coimbra, Lloyd-Braga and Modesto (2005), the emphasis has not been in the precise analysis of stability and dynamics. Therefore we focus on these issues by extending the model of Devereux and Lockwood (1991). We use the RTM wage bargaining and derive labour demand given the flexible wage negotiation after capital stock decided by firms in a closed economy $\mathrm{OG}$ framework by incorporating imperfectly competitive labour markets via Nash wage bargaining. Wage bargaining takes place between the young workers and the old capitalists.

We demonstrate the following results. With Cobb-Douglas utility and production functions the economy's steady state is unique under imperfectly competitive labour markets, and the steady state capital stock depends positively on the trade union's bargaining power and the wage elasticity of labour demand. That elasticity depends positively on the size of decreasing returns to scale and/or of degree of product market competition. This happens because higher bargaining power of the trade union will induce workers to save more, which boosts the capital stock. Higher wage elasticity increases the level of capital stock, and lowers the share price initially. There is also a positive relationship between the capital stock and the share price in the capital market equilibrium. Finally, we study the dynamics of the model and show that the steady state equilibrium is a saddle.

We proceed as follows. In section 2 we present the basic framework and comparative statics of an overlapping generations model under Nash wage bargaining, where wages are negotiated after the capital stock decision. Section 3 analyses the steady state equilibrium and dynamics under flexible wage negotiation. Finally, there is a concluding section where we briefly summarize our findings. 


\section{An Overlapping Generations Model under Wage Bargaining}

We study an overlapping generations model without population growth (i.e. population is normalized to be unity) and with perfect foresight. The young in each period are endowed with one unit of time, which they inelastically supply to the market. Their retirement consumption is provided by their savings, which can be invested in two assets. They supply capital to the firms, and also buy shares of those firms. There is an operative stock market, because of the existence of trade unions and decreasing returns to scale due either to technology or imperfectly competitive product markets. ${ }^{1}$

We incorporate imperfect competition in labour markets into an overlapping generations model. The young workers form a labour union. They negotiate about the wage with the firm's owners. There is right-to-manage, and thus employment is determined by firms (for alternative formulations of trade union models, see e.g. Cahuc and Zylberberg (2004), chapter 7).

As in Devereux and Lockwood (1991) we assume that the worker-consumers have the following Cobb-Douglas utility function

$$
u\left(c_{1}^{t, i}, c_{2}^{t, i}\right)=\left(c_{1}^{t, i}\right)^{\lambda}\left(c_{2}^{t, i}\right)^{1-\lambda}, 0<\lambda<1,
$$

where $c_{j}^{t, i}$ refers to the consumption of the person born at the beginning of period $t$ in the $j^{\text {th }}$ period of his life $(j=1,2)$ if he is either employed $(i=E)$ or unemployed $(i=U)$. The young of each generation are endowed with a unit of labour which they supply inelastically. The periodic budget constraints of the employed person are

$$
\begin{gathered}
c_{1}^{t, E}+k_{t+1}^{E}+q_{t} \theta_{t+1}^{E}=w_{t}(1-\tau) \\
c_{2}^{t, E}=R_{t+1} k_{t+1}^{E}+\left(d_{t+1}+q_{t+1}\right) \theta_{t+1}^{E} .
\end{gathered}
$$

The unemployed person's constraints are respectively

$$
\begin{aligned}
& c_{1}^{t, U}+k_{t+1}^{U}+q_{t} \theta_{t+1}^{U}=b_{t} \\
& c_{2}^{t, U}=R_{t+1} k_{t+1}^{U}+\left(d_{t+1}+q_{t+1}\right) \theta_{t+1}^{U} .
\end{aligned}
$$

1 There is empirical evidence that product market regulation has been eased, and thereby competition has increased in OECD countries recently (see Convay and Janod and Nicoletti 2005). 
The young can save in two assets. $k_{t+1}^{i}$ denotes the supply of capital and $\theta_{t+1}^{i}$ the number of shares bought by consumer of type $i . q_{t}$ is the price of a share in period $t$, and $d_{t+1}$ denotes the dividend per share paid in period $t+1 \cdot w_{t}$ is the wage rate, $\tau$ is the proportional tax rate on labour income and $b_{t}$ is the unemployment insurance compensation financed by the proceeds from the labour tax. $R_{t+1}$ is the interest factor (and the gross return on capital) between periods $\mathrm{t}$ and $t+1$. Because there is no uncertainty, there is an obvious arbitrage condition here, which says that the return on investing in capital should be equal to investing in the shares of the firms, i.e. $R_{t+1}=\left(d_{t+1}+q_{t+1}\right) / q_{t}$. This means that the lifetime budget constraint is $c_{1}^{t, i}+c_{2}^{t, i} / R_{t+1}=I_{t}^{i}$, where $I_{t}^{i}$ denotes the income of the type $i$ worker-consumer.

We can define total savings as $s_{t}^{i}=k_{t+1}^{i}+q_{t} \theta_{t+1}^{i}$. Given the utility function (1) the saving can be solved to get $s_{t}^{i}=(1-\lambda) I_{t}^{i}$, where $\lambda$ is constant. This means that total savings do not depend on the interest factor, because with Cobb-Douglas utility function the substitution and income effect cancel each other out. We can thus write the indirect utility functions of both types as

$$
\begin{aligned}
& V^{E}(w, R)=\lambda^{\lambda}(1-\lambda)^{1-\lambda} R^{1-\lambda} w=\hat{\lambda} R^{1-\lambda} w(1-\tau) \\
& V^{U}(w, R)=\lambda^{\lambda}(1-\lambda)^{1-\lambda} R^{1-\lambda} b=\hat{\lambda} R^{1-\lambda} b,
\end{aligned}
$$

where $\hat{\lambda}=\lambda^{\lambda}(1-\lambda)^{1-\lambda}$. Thus the utility depends positively both on alternative wage income and the rate of return on savings.

The firms are assumed to have the following revenue function: $F(K, L)^{\mu}=\left(K^{\alpha} n^{1-\alpha}\right)^{\mu}$, with $0<\alpha<1$ and $0<\mu<1$. One can give at least two different justifications for the restriction on parameter $\mu$. One justification for the revenue function is that the production function has decreasing returns-to-scale so that $\mu<1$. Alternatively the specification $F(K, L)^{\mu}=\left(K^{\alpha} n^{1-\alpha}\right)^{\mu}$ can be justified by assuming that (a) the production technology has a property of constant returns to scale in terms of capital and labour, but (b) product markets are imperfectly competitive. Assuming e.g. an iso-elastic demand function $D(p)=p^{-\varepsilon}$ ( $p$ is the 
product price), we can write the firm's gross revenue function as $p F=F^{1-(1 / \varepsilon)}$, where the price elasticity of product demand is higher than one, but less than infinity because $\mu=1-(1 / \varepsilon)<1$ (see e.g. Dixit and Stiglitz 1977, Blanchard and Giavazzi, 2003, and Spector 2004).

The firms rent capital and hire labour from consumers. The profits are

$$
\Pi_{t}=F\left(K_{t}, L_{t}\right)^{\mu}-w_{t} n_{t}-r_{t} K_{t} .
$$

We assume for simplicity that capital does not depreciate at all within the period. We will consider the case of what Devereux and Lockwood (1991) call a non-binding solution. This means that firms have committed to a level of capital stock before they negotiate about the wage (see also de la Croix and Licandro (1995)). In a recent study Hellwig (2004) has compared a number of key properties associated with two alternative timing structures between negotiated wage setting and investment decisions within the framework of an intertemporal general equilibrium model. He suggests that although the long-term labour demand with endogenous investment is more elastic than the short-term demand, it does not necessarily lead to a less aggressive wage policy. The wage-employment trade-off in his model depends on whether the elasticity of substitution in production is lower than or higher than the inverse of the elasticity of marginal utility in consumption. Our present analysis does not address this hold-up problem. That might be important, if firms can adjust their investment decisions in the short run.

The first-order condition for employment with a given level of capital stock is (dropping the time subscripts for convenience)

$$
(1-\alpha) \mu K^{\alpha \mu} n^{(1-\alpha) \mu-1}=w .
$$

Solving the labour demand we get

$$
n=(1-\alpha)^{\eta} \mu^{\eta} K^{\alpha \mu \eta} w^{-\eta}=B^{\eta} K^{\alpha \mu \eta} w^{-\eta},
$$

where $\eta=-n_{w} w / n=1 /[1-\mu(1-\alpha)]$, which is greater than unity because $0<\mu, \alpha<1$ and $B=(\eta-1) / \eta$. Labour demand depends negatively on wage, and positively on capital stock, since capital and labour are complements in production, i.e. $F_{n K}>0$. These effects are stronger, if $\mu$ becomes higher. 
The representative firm and the trade union negotiate about the wage given that the firm decides labour demand. Using RTM approach the negotiated wage rate can then be solved from the following Nash bargaining problem

$$
\underbrace{\operatorname{Max}}_{w_{t}} \Omega_{t}=\left(U_{t}-\bar{U}_{t}\right)^{\beta}\left(\Pi_{t}-\bar{\Pi}_{t}\right)^{1-\beta} \text { s.t. } n=B^{\eta} K^{\alpha \mu \eta} w^{-\eta},
$$

where $U_{t}\left(\bar{U}_{t}\right)$ denotes the utility (fallback utility) of the trade union, $\bar{\Pi}_{t}$ is the fallback profit of the firm and $\beta$ denotes the relative bargaining power of trade union. ${ }^{2}$ Trade union cares about the employed and unemployed. Thus we assume that $U_{t}=n_{t} V_{t}^{E}+\left(1-n_{t}\right) V_{t}^{U}$. Since an unemployed person gets an unemployment insurance compensation we assume that $\bar{U}_{t}=V_{t}^{U}$. Given the fact that firms have committed to the level of capital stock before wage negotiations, they have to pay the rentals even in the case of no agreement. This means that $\bar{\Pi}_{t}=-r_{t} K_{t}$.

Incorporating the fallback utility and profit into $(\mathrm{PN})$ we can now rewrite the RTM Nash bargaining problem as

$\left(\mathrm{PN}^{\prime}\right) \quad \underbrace{\operatorname{Max}}_{w_{t}} \Omega_{t}=\left[\hat{\lambda} R_{t+1}^{1-\lambda}\left(w_{t}(1-\tau)-b_{t}\right) n_{t}\right]^{\beta}\left[F\left(K_{t}, n_{t}\right)^{\mu}-w_{t} n_{t}\right]^{1-\beta}$

$$
\text { s.t. } n=B^{\eta} K^{\alpha \mu \eta} w^{-\eta} \text {. }
$$

The first-order condition reduces to

$$
\frac{\beta\left[w_{t}(1-\tau)(1-\eta)+b_{t} \eta\right]}{w_{t}(1-\tau)-b_{t}}=\frac{(1-\beta) w_{t} n_{t}}{F\left(K_{t}, n_{t}\right)^{\mu}-w_{t} n_{t}} .
$$

Given the production function, equation (8) can be expressed in a standard way as

$$
w_{t}^{N}=\frac{[\beta+\eta-1]}{[\eta-1]} \hat{b}_{t}
$$

where $\hat{b}_{t}=b_{t} /(1-\tau)$. The negotiated wage depends positively on the level of unemployment insurance compensation, $b$, the labour income tax, $\tau$, and the trade

2 The Nash maximand (PN' below), i.e. the weighted product of the net gains of the bargainers, can be justified both via the axiomatic approach by Nash (1950) and via the strategic approach by Rubinstein (1982). These approaches are of course very different, but interestingly, Nash's axiomatic solution can also be obtained as a limit solution to a non-cooperative game in which the time interval between alternative offers approaches zero (see Binmore et. al, 1986 for a proof of this assertion). 
union's relative bargaining power, $\beta$, while negatively on the wage elasticity of labour demand, $\eta$. This becomes higher either with more intensified product market competition, i.e. when price elasticity of product demand $\varepsilon$ is higher, and/or with smaller decreasing returns to scale. It is important to keep in mind that in the case of Cobb-Douglas production function the negotiated wage does not depend on the level of capital stock, since the wage elasticity of labour demand only depends on the parameters $\mu=1-\frac{1}{\varepsilon}$ and $\alpha$. In what follows we denote the mark-up between the negotiated wage and unemployment insurance compensation as $(\beta+\eta-1) /(\eta-1) \equiv A(>1)$.

The negotiated wage means that the share of output going to the employed workers (i.e. $w_{t}^{N} n_{t}$ ) is

$$
w^{N} n=B^{\eta} K^{\alpha \mu \eta} A^{1-\eta} \hat{b}^{1-\eta} .
$$

The share of output going to the owners $\left(F^{\mu}-w n\right)$ can be expressed as follows

$$
\begin{aligned}
& F(K, n)^{\mu}-w^{N} n=B^{\eta-1} K^{\alpha \mu \eta} A^{1-\eta} \hat{b}^{1-\eta} \\
& -B^{\eta} K^{\alpha \mu \eta} A^{1-\eta} \hat{b}^{1-\eta}=B^{\eta-1} K^{\alpha \mu \eta} A^{1-\eta} \hat{b}^{1-\eta}[1-B]
\end{aligned}
$$

Thus we can rewrite equation (11) as follows

$$
F(K, n)^{\mu}-w^{N} n=B^{\eta-1} K^{\alpha \mu \eta} A^{1-\eta} \hat{b}^{1-\eta}[1-B] .
$$

We can now write dividends ( $D i v=F^{\mu}-w n-r K$ ) as

$$
\text { Div }=B^{\eta-1} K^{\alpha \mu \eta} A^{1-\eta} \hat{b}^{1-\eta}[1-B]-r K .
$$

We note $\quad B^{\eta-1} A^{1-\eta} \hat{b}^{1-\eta}[1-B] \equiv H>0 \quad$ so that $\quad D i v=K^{\alpha \mu \eta} H-r K$, where $\alpha \mu \eta=\alpha \mu /(1-\mu(1-\alpha))<1$. Dividend is a strictly concave function of the capital stock, and fulfils the conditions $\lim _{K \rightarrow 0} \frac{\partial D i v}{\partial K}=\infty$ and $\lim _{K \rightarrow \infty} \frac{\partial D i v}{\partial K}=-r$. There is then an interior maximizing solution given that $H>0$. The first-order condition for the optimal capital stock is

$$
\alpha \mu \eta K^{\alpha \mu \eta-1} H=r .
$$

We use this to compute the dividend by substituting the LHS of (14) for $r$ in (13) to obtain

$$
\operatorname{Div}=K^{\alpha \mu \eta} H(1-\alpha \mu \eta)=K^{\alpha \mu \eta} H(1-\mu) \eta .
$$


The partial derivatives of $H$ are: $H_{A}<0, H_{b}<0$ and $H_{\tau}<0$. We also note that $H_{B} \equiv A^{1-\eta} \hat{b}^{1-\eta}[\eta(1-B)-1]$ so that $H_{B}=0$, since $\eta(1-B)=1$. The signs of derivatives are intuitive. A higher mark-up, higher unemployment insurance compensation and higher labour income tax increase the wage demand, and thus have a negative effect on dividends.

In the next section we explore stability and dynamics under flexible RTM wage negotiation.

\section{Steady States and Dynamical Equilibria under Flexible Wage Negotiation}

We can now characterize the equilibrium of this economy. Saving must be allocated to the capital stock and the shares of the firm. The second equilibrium condition is the arbitrage condition for the returns from investing in the capital stock and the shares. The total capital stock $\left(K_{t+1}\right)$ must be equal to the amount saved to capital by the employed and unemployed workers (i.e. $n_{t} k_{t+1}^{E}+\left(1-n_{t}\right) k_{t+1}^{U}$ ). We normalize the aggregate number of shares to be unity, i.e. that $n_{t} \theta_{t+1}^{E}+\left(1-n_{t}\right) \theta_{t+1}^{U}=1$. Given this normalization and the utility function (i.e. the saving behaviour) we get the following capital market equilibrium condition $K_{t+1}=(1-\lambda)\left[n_{t} w_{t}(1-\tau)+\left(1-n_{t}\right) b_{t}\right]-q_{t}$. We assume that government uses the balanced-budget rule according to which it does not independently determine both expenditures and level of taxes required to finance expenditures. Therefore, the unemployment insurance payment is assumed to finance by the labour income taxation of employed workers, i.e. $\left(1-n_{t}\right) b_{t}=\tau n_{t} w_{t}{ }^{3}$ Using this assumption the capital market equilibrium condition can be expressed as

$$
K_{t+1}=(1-\lambda)\left(n_{t} w_{t}\right)-q_{t} .
$$

The arbitrage condition,

$$
q_{t+1}=\left(1+r_{t+1}\right) q_{t}-d_{t+1}
$$

is the other equilibrium condition.

This specification for financing the unemployment benefit has been used e.g. by Rocheteau (1999a), (1999b) in matching models of equilibrium unemployment. 
Given the negotiated wage (9), the first-order condition for an optimal capital stock (14), and the dividend as a function of the capital stock (15), we get the following dynamical system for the capital stock and the share price

$$
\begin{aligned}
& K_{t+1}=(1-\lambda)\left\lfloor K_{t}^{\alpha \mu \eta}(A \hat{b})^{-\eta} B^{\eta}\right\rfloor-q_{t} \\
& q_{t+1}=\left[1+\alpha \mu \eta K_{t+1}^{\alpha \mu \eta-1}\right] q_{t}-K_{t+1}^{\alpha \mu \eta} H(1-\mu) \eta .
\end{aligned}
$$

In the steady state $\left(\Delta K_{t}=0\right.$ and $\left.\Delta q_{t}=0\right)$ we have

$$
\begin{aligned}
& q=(1-\lambda)\left[K^{\alpha \mu \eta}(A \hat{b})^{-\eta} B^{\eta}\right]-K \equiv G(K) \\
& q=\frac{K^{\alpha \mu \eta} H(1-\mu) \eta}{\alpha \mu \eta K^{\alpha \mu \eta-1} H}=\frac{1-\mu}{\alpha \mu} K .
\end{aligned}
$$

The first equation describing the capital market equilibrium condition in steady state is nonlinear, while the second one, describing the arbitrage condition, is linear. We note from (20) that $G(0)=0$ and $G^{\prime}(K)=(1-\lambda)(\alpha \mu \eta)(A \hat{b})^{-\eta} B^{\eta} K^{\alpha \mu \eta-1}-1$. We can see that $\lim _{K \rightarrow 0} G^{\prime}(K)=\infty$ and $\lim _{K \rightarrow \infty} G^{\prime}(K)=-1$. One can see that the slope of (21) decreases, when the elasticity of output with respect to capital stock $(\alpha \mu)$ increases. These properties imply that we can draw the following diagram, which shows that the steady state $\left(K^{*}\right)$ is unique.

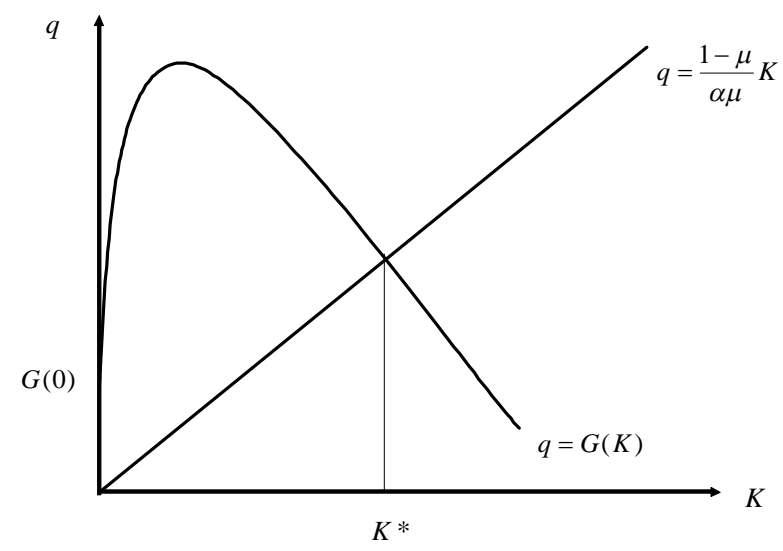

Figure 1. Steady state.

We collect the previous findings in: 
Proposition 1: With Cobb-Douglas utility and production functions the steady state of the OG economy described by equations (20) and (21) is unique, when wages are decided by the RTM bargaining before the capital stock.

What happens to the steady state capital stock, when trade union's bargaining power is higher or wage elasticity of labour demand is stronger due either to smaller decreasing returns to scale and/or to more intensive product market competition? Bargaining power affects only the first steady state equation (20), while wage elasticity of labour demand affects both equations (20) and (21). We present the result in:

Proposition 2: With Cobb-Douglas utility and production functions, and with RTM bargaining before the capital stock decision, the steady state capital stock is higher (a) the bigger is the trade union's bargaining power and $(b)$ the stronger is the wage elasticity.

Proof: (a) The bargaining power, $\beta$, affects the curve (20) through the term $A=(\beta+\eta-1) /(\eta-1)$ positively since $A_{\beta}=1 /(\eta-1)>0$. This means that the curve (20) shifts up, when the bargaining power is increased, and thus the steady state capital stock increases. For the proof of part (b), see Appendix 1. Q.E.D.

Proposition 2 (a) follows from the fact that the improved bargaining power will induce workers to save more, ceteris paribus, which in turn boosts the capital stock. Part (b) of Proposition follows from a couple of considerations. First, stronger wage elasticity increases the level of capital stock, and lowers the share price initially via the arbitrage condition (see equation 21). On the other hand, there is a positive relationship between the capital stock and the share price in the capital market equilibrium as we show in Appendix 1. Therefore stronger wage elasticity increases the steady state capital stock.

Next we study the dynamics of the model by considering paths for which $K_{t+1} \geq K_{t}$ and $q_{t+1} \geq q_{t}$. It follows from (18) that

$$
\begin{aligned}
& K_{t+1} \geq K_{t} \Leftrightarrow(1-\lambda)\left[K_{t}^{\alpha \mu \eta}(A \hat{b})^{-\eta} B^{\eta}\right]-q_{t} \geq K_{t} . \\
& \left.\Rightarrow q_{t} \leq(1-\lambda) \mid K_{t}^{\alpha \mu \eta}(A \hat{b})^{-\eta} B^{\eta}\right]-K_{t} \equiv M\left(K_{t}\right) .
\end{aligned}
$$


We note that capital stock is growing below the curve $q_{t}=M\left(K_{t}\right)$.

It follows from (19) for the dynamics of the arbitrage equation that (see Appendix 2)

$$
\left.q_{t} \geq(1-\mu) \eta(1-\lambda) \mid K_{t}^{\alpha \mu \eta}(A \hat{b})^{-\eta} B^{\eta}\right] \equiv Q\left(K_{t}\right) .
$$

The share price is increasing above the curve $q_{t}=Q\left(K_{t}\right)$. Differentiating (22) and (23) with respect to $K$ we obtain

$$
\begin{aligned}
& M^{\prime}(K)=(1-\lambda)(\alpha \mu \eta)(A \hat{b})^{-\eta} B^{\eta} K^{\alpha \mu \eta-1}-1 \\
& Q^{\prime}(K)=\alpha \mu(1-\mu) \eta^{2}(1-\lambda)(A \hat{b})^{-\eta} B^{\eta} K^{\alpha \mu \eta-1}
\end{aligned}
$$

Both functions are strictly concave, and $M(K)$ has a maximum. Furthermore, we note that $M(0)=Q(0)=0, \quad \lim _{K \rightarrow 0} M^{\prime}(K)=\infty$ and $\lim _{K \rightarrow 0} Q^{\prime}(K)=\infty$. In addition we have that $\lim _{K \rightarrow \infty} M^{\prime}(K)=-1$ and $\lim _{K \rightarrow \infty} Q^{\prime}(K)=0$. We have already proved that the steady state is unique. Thus we can depict the qualitative features of our model in Figure 2. The Figure indicates that the steady state is a saddle.

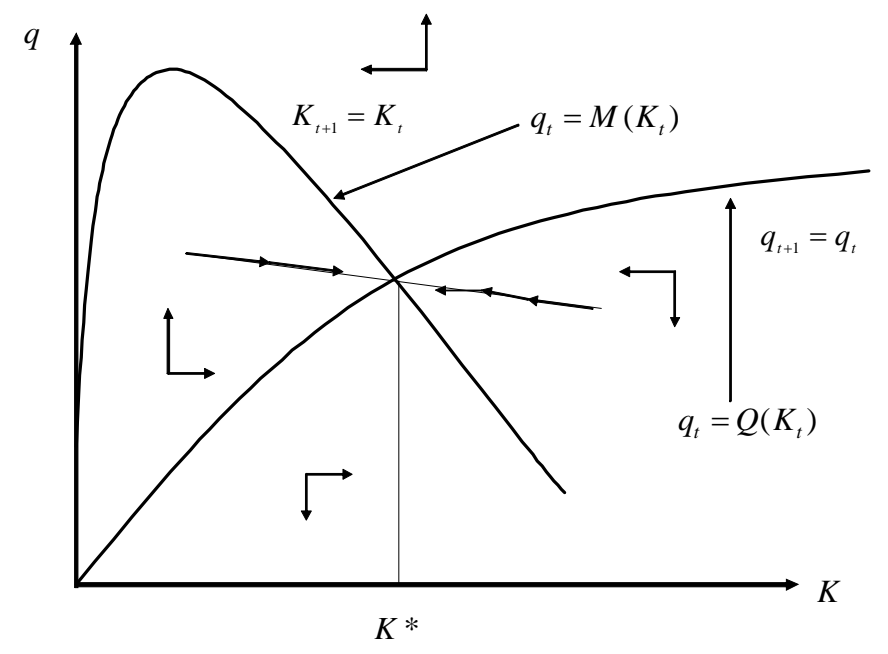

Figure 2. Dynamics.

To study formally the stability properties of dynamical equilibrium, we rewrite equation (18) as follows

$$
\left.K_{t+1}=(1-\lambda) \mid K_{t}^{\alpha \mu \eta}(A \hat{b})^{-\eta} B^{\eta}\right]-q_{t} \equiv Z\left(K_{t}, q_{t}\right) .
$$

Substituting the RHS of (26) for $K_{t+1}$ in (19) gives an implicit equation for $q_{t+1}$, 


$$
q_{t+1}=P\left(K_{t}, q_{t}\right) .
$$

The planar system describing the dynamics of the capital stock and the share price consists now of equations (26) and (27). The Jacobian matrix of the partial derivatives of the system (26)-(27) can be written as

(28) $J=\left[\begin{array}{ll}Z_{K} & Z_{q} \\ P_{K} & P_{q}\end{array}\right]$,

where

$$
\begin{aligned}
& Z_{K}=(1-\lambda)\left[(\alpha \mu \eta) K^{\alpha \mu \eta-1}(A \hat{b})^{-\eta} B^{\eta}\right] \\
& Z_{q}=-1 \\
& P_{q}=1+\alpha \mu \eta K^{\alpha \mu \eta-1} H-\frac{\partial q_{t+1}}{\partial K_{t+1}} \\
& P_{K}=-(A \hat{b})^{-\eta} B^{\eta} \eta^{2}(1-\mu)(1-\lambda) \alpha \mu H K^{2(\alpha \mu \eta-1)}<0 .
\end{aligned}
$$

In Appendix 3 we present details of these derivations.

We prove the following

Proposition 3: The steady state equilibrium, with RTM bargaining before the capital stock decision under imperfectly competitive labour market, is a saddle.

Proof. See Appendix 4.

This saddle point for the steady state equilibrium seems to result from the constant mark-up in wage negotiation due to Cobb-Douglas production function. Coimbra, Lloyd-Braga and Modesto (2005) used efficient bargaining in an OG model with firm-specific negotiation and showed that local Hop bifurcation may occur when elasticity of substitution between capital and labour is sufficiently high with the CES production function.

\section{Conclusions}

We have explored the stability and dynamics in an overlapping generations economy with wage bargaining under imperfectly competitive labour markets. Under right-to manage bargaining, where employment is not negotiated but decided by firms, we have assumed that wage is negotiated given the capital stock and that 
wage bargaining process takes place between the young workers and the old capitalists. We have provided the following results.

With Cobb-Douglas utility and production functions the economy's steady state is unique and the steady state capital stock depends positively on the trade union's bargaining power. The bigger bargaining power of the trade union will induce workers to save more, which boosts the capital stock. Moreover, the higher wage elasticity of labour demand, which is due either to smaller decreasing returns to scale and/or to more intensive product market competition, raises the capital stock, and lowers the share price initially. On the other hand, there is a positive relationship between the capital stock and the share price in the capital market equilibrium. Therefore a higher wage elasticity increases the capital stock. Finally, we study the dynamics of the model and show that in this OG framework with RTM bargaining before the capital stock decision under imperfectly competitive labour market the steady state equilibrium is a saddle.

An interesting further research topic associated with OG framework would be to analyse these issues both in the open economy framework (for one such an OG specification, see Bertocchi 2003) and also to allow for the presence of strategic or flexible international outsourcing of economic activities under imperfectly competitive labour markets (see e.g. Egger and Egger 2005, Glass and Saggi 2001, and Skaksen 2004).

\section{Appendix 1: The proof of part (b) of Proposition 2.}

The total effect of wage elasticity on the capital stock can be obtained by considering the effects of product market competition and/or change in decreasing returns to scale on equations (20) and (21). Differentiating $(1-\mu) / \alpha \mu$ in (21) with respect to $\mu$ gives $\frac{\partial}{\partial \mu}\left[\frac{1-\mu}{\alpha \mu}\right]=\frac{-1}{\alpha \mu^{2}}<0$. Considering the effect of $\mu$ on $G(K)$ in (20) we first note that there is a positive relationship between $\mu$ and $\eta$. We can rewrite (20) in terms of $\eta$ as follows

(A1) $q=(1-\lambda) X-K$,

where

(A2) $X=K^{\alpha \mu \eta}\left(\frac{\beta+\eta-1}{\eta-1}\right)^{-\eta} \hat{b}^{-\eta}\left(\frac{\eta-1}{\eta}\right)^{\eta}\left(\frac{\beta}{\eta-1}\right)=K^{\alpha \mu \eta}(\beta+\eta-1)^{-\eta} \hat{b}^{-\eta}(\eta-1)^{2 \eta} \eta^{-\eta}$

This can be expressed in the logarithmic form as follows 
(A3) $\ln X=\alpha \mu \eta \ln K-\eta \ln \hat{b}-\eta \ln (\beta+\eta-1)+2 \eta \ln (\eta-1)-\eta \ln \eta$.

Differentiating (A3) with respect to $\eta$ gives

$$
\frac{\partial}{\partial \eta} \ln X=\frac{X_{\eta}}{X}=\alpha \mu \ln K-\ln \hat{b}-\ln (\beta+\eta-1)-\frac{\eta}{\beta+\eta-1}+2 \ln (\eta-1)+\frac{2 \eta}{\eta-1}-\ln \eta-1
$$

Using $-\frac{\eta}{\beta+\eta-1}+\frac{2 \eta}{\eta-1}-1=\frac{\beta(1+\eta)+(\eta-1)}{(\eta-1)(\beta+\eta-1)}$ and $y=e^{\ln y}$ we can rewrite the RHS of (A4) as

(A5) $K^{\alpha \mu} \hat{b}^{-1}(\beta+\eta-1)^{-1}(\eta-1)^{2} \eta^{-1} e^{\frac{\beta(1+\eta)+(\eta-1)}{(\eta-1)(\beta+\eta-1)}}>0$.

Therefore $G(K)$ depends positively on $\eta$ so that in our model there is a positive relationship between the steady state capital, $K^{*}$, and the wage elasticity. Q.E.D.

Appendix 2: The dynamics of the arbitrage equation.

Equation (19) implies that

$$
\begin{aligned}
& q_{t+1} \geq q_{t} \Leftrightarrow\left[1+\alpha \mu \eta K_{t+1}^{\alpha \mu \eta-1} H\right] q_{t}-K_{t+1}^{\alpha \mu \eta} H(1-\mu) \eta \geq q_{t} \\
& \Rightarrow \quad q_{t} \geq \frac{K_{t+1}^{\alpha \mu \eta} H(1-\mu) \eta}{\alpha \mu \eta K_{t+1}^{\alpha \mu \eta-1} H}=\frac{1-\mu}{\alpha \mu} K_{t+1},
\end{aligned}
$$

because $\eta(1-\mu+\alpha \mu)=1$. We have thus obtained that $q_{t+1} \geq q_{t}$ implies that $q_{t} \geq((1-\mu) / \alpha \mu) K_{t+1}$. To go on to analyse the paths, where $q_{t+1} \geq q_{t}$, we substitute the expression for $K_{t+1}$ from equation (18) and obtain

$$
q_{t} \geq \frac{1-\mu}{\alpha \mu}\left\{(1-\lambda)\left[K_{t}^{\alpha \mu \eta}(A \hat{b})^{-\eta} B^{\eta}\right]-q_{t}\right\},
$$

which can be rewritten in equation (23). Q.E.D.

\section{Appendix 3: Derivation of the partials of the Jacobian matrix.}

We rewrite equation (19) as follows

(A8) $\quad q_{t+1}=q_{t}+\alpha \mu \eta K_{t+1}^{\alpha \mu \eta-1} H q_{t}-(1-\mu) \eta K_{t+1}^{\alpha \mu \eta} H$.

We first compute $P_{q}$ and evaluate it at the steady state to get

(A9) $P_{q}=1+\alpha \mu \eta K^{\alpha \mu \eta-1} H-\frac{\partial q_{t+1}}{\partial K_{t+1}}$, 
since from the analysis in the text we know that $\partial K_{t+1} / \partial q_{t}=-1$. Computing from (A8) we get

(A10)

$$
\begin{aligned}
\frac{\partial q_{t+1}}{\partial K_{t+1}} & =(\alpha \mu \eta)(\alpha \mu \eta-1) K^{\alpha \mu \eta-2} H q-\alpha \mu(1-\mu) \eta^{2} K^{\alpha \mu \eta-1} H \\
& =\alpha \mu \eta K^{\alpha \mu \eta-2} H[(\alpha \mu \eta-1) q-(1-\mu) \eta K]=-(1-\mu) \eta K^{\alpha \mu \eta-1} H<0 .
\end{aligned}
$$

This means that

(A11) $P_{q}=1+K^{\alpha \mu \eta-1} H$

Next we compute $P_{K}$. From (A10) we want to compute $\frac{\partial q_{t+1}}{\partial K_{t+1}} \frac{\partial K_{t+1}}{\partial K_{t}} \quad\left(=P_{K}\right)$. We have $\partial q_{t+1} / \partial K_{t+1}$ from (A11), and get from (26)

$$
\frac{\partial K_{t+1}}{\partial K_{t}}=(1-\lambda)(\alpha \mu \eta)(A b)^{-\eta} B^{\eta} b(A-1) K^{\alpha \mu \eta-1}
$$

Thus we get

$$
P_{K}=-(A \hat{b})^{-\eta} B^{\eta} \eta^{2}(1-\mu)(1-\lambda) \alpha \mu H K^{2(\alpha \mu \eta-1)}<0 .
$$

We can also express this as $P_{K}=-(1-\mu) Z_{K} \eta H K^{\alpha \mu \eta-1}$. Q.E.D.

\section{Appendix 4: Proof of Proposition 3.}

We analyze the stability of the system (18) and (19), which characterizes the dynamics of the capital stock and the share price. The characteristic polynomial associated with the system (26) and (27) expressed in terms of D and T is

(A14) $\quad p(\lambda)=\lambda^{2}-T \lambda+D=0$

It is known from the stability theory of difference equations (see e.g. Azariadis, 1993, pp. 63-67, and de la Croix and Michel, 2002, pp. 321-322) that for a saddle point to exist the roots of $p(\lambda)=0$ need to be on both sides of (minus and plus) unity. Thus for a saddle we need that D-T $+1<0$ and $\mathrm{D}+\mathrm{T}+1>0$ or D-T $+1>0$ and $\mathrm{D}+\mathrm{T}+1<0$.

The planar system describing the dynamics of the capital stock and the share price consists now of equations (26) and (27). The Jacobian matrix of the partial derivatives of the system can be written as

(A15) $J=\left[\begin{array}{ll}Z_{K} & Z_{q} \\ P_{K} & P_{q}\end{array}\right]$,

where

$$
\begin{aligned}
& Z_{K}=(1-\lambda)\left\lfloor(\alpha \mu \eta) K^{\alpha \mu \eta-1}(A \hat{b})^{-\eta} B^{\eta}\right\rfloor>0 \\
& Z_{q}=-1 \\
& P_{K}=-(1-\mu) Z_{K} \eta H K^{\alpha \mu \eta-1} \\
& P_{q}=1+K^{\alpha \mu \eta-1} H .
\end{aligned}
$$


Computing the trace $\left(T=Z_{K}+P_{q}\right)$ and determinant $\left(D=Z_{K} P_{q}-Z_{q} P_{K}=Z_{K} P_{q}+P_{K}\right)$ we obtain

(A16) $T=(1-\lambda)\left[(\alpha \mu \eta) K^{\alpha \mu \eta-1}(A \hat{b})^{-\eta} B^{\eta}\right]+1+K^{\alpha \mu \eta-1} H>1$

$$
\begin{aligned}
& D=Z_{K} P_{q}-(1-\mu) Z_{K} \eta H K^{\alpha \mu \eta-1}=Z_{K}\left[1+K^{\alpha \mu \eta-1} H-\eta(1-\mu) K^{\alpha \mu \eta-1} H\right]= \\
& Z_{K}\left[1+K^{\alpha \mu \eta-1} H(1-\eta(1-\mu)]=Z_{K}\left[1+K^{\alpha \mu \eta-1} H(\alpha \mu \eta)\right]>0 .\right.
\end{aligned}
$$

Now we conclude that $D+T+1>0$. Next we compute $D-T+1$ to get

$$
D-T+1=-K^{\alpha \mu \eta-1} H\left[1-\alpha \mu \eta Z_{K}\right]
$$

Rewriting we get

$$
D-T+1=-K^{\alpha \mu \eta-1} H\left[1-(1-\lambda)(\alpha \mu \eta)^{2} K^{\alpha \mu \eta-1}(A \hat{b})^{-\eta} B^{\eta}\right] .
$$

We next develop the term $(1-\lambda)(\alpha \mu \eta)^{2} K^{\alpha \mu \eta-1}(A \hat{b})^{-\eta} B^{\eta}$ from (A12), and denote it by $Y$. Using the steady state relations (20) and (21) we can express $Y$ as follows

(A20) $\quad Y(\bullet)=\frac{(1-\lambda)(\alpha \mu \eta)^{2} K^{\alpha \mu \eta}(A \hat{b})^{-\eta} B^{\eta}}{K}=\alpha \mu \eta$

Therefore $D-T+1=-K^{\alpha \mu \eta-1} H(1-\alpha \mu \eta)<0$, and thus we have a saddle. Q.E.D.

\section{References:}

Anderson, S.P. and M.B. Devereux [1988]: "Trade Unions and the Choice of Capital Stock", Scandinavian Journal of Economics 90(1), 27-44.

Anderson, S.P. and M.B. Devereux [1991]: "The Trade-off between Precommitment and Flexibility in Trade Union Wage Setting", Oxford Economic Papers 43, 549-569.

Azariadis, C. [1993]: Intertemporal Macroeconomics, Blackwell, Oxford.

Bertocchi, G. [2003]: "Labor Market Institutions, International Capital Mobility, and the Persistence of Underdevelopment", Review of Economic Dynamics 6, 637-650.

Binmore, K., Rubinstein, A. and A. Wolinsky [1986]: "The Nash Solution in Economic Modeling", Rand Journal of Economics 17(2), 176-188.

Blanchard, O. and F. Giavazzi [2003]: "Macroeconomic Effects of Regulation and Deregulation in Goods and Labor Markets", Quarterly Journal of Economics 118, 879-907.

Cahuc, P. and A. Zylberberg [2004]: Labor Economics, MIT Press.

Coimbra, R., T. Lloyd-Braga and L. Modesto [2005]: "Endogenous Fluctuations in Unionized Economies with Productive Externalities", Economic Theory 26, 629-649.

Conway, P., V. Janod and G. Nicoletti [2005]: "Product Market Regulation in OECD Countries: 1998 to 2003", OECD Economics Department Working Papers No. 419. 
de la Croix, D. and O. Licandro [1995]: "Underemployment, Irreversibilities and Growth under Trade Unionism”, Scandinavian Journal of Economics 97, 385-399.

de la Croix, D. and P. Michel [2002]: A Theory of Economic Growth: Dynamics and Policy in Overlapping Generations, Cambridge University Press.

De Palma, F. and T. Seegmuller [2004]: "Unions, Wage Differential and Indeterminacy", Research in Economics 58, 205-218.

Devereux, M.B. and B. Lockwood [1991]: "Trade Unions, Non-binding Wage Agreements, and Capital Accumulation”, European Economic Review 35, 1411-1426.

Diamond, P. [1965]: "National Debt in a Neoclassical Growth Model”, American Economic Review 55, 1026-1050.

Dixit, A.K. and J.E. Stiglitz [1977]: "Monopolistic Competition and Optimum Product Diversity", American Economic Review 67, 297-308.

Dos Santos Ferreira, R. and T. Lloyd-Braga [2002]: "Can Market Power Sustain Endogenous Growth in Overlapping Generations Economies?", Economic Theory 20, 199-205.

Egger, H. and P. Egger [2005]: "Labor Market Effects of Outsourcing under Industrial Interdependence", International Review of Economics and Finance 14, 349-363.

Glass, A.J. and K. Saggi [2001]: "Innovation and Wage Effects of International Outsourcing", European Economic Review 45, 67-86.

Grout, P.A. [1984]: "Investment and Wages in the Absence of Binding Contracts: A Nash Bargaining Approach", Econometrica 52, 449-460.

Hellwig, M. [2004]: "The Relation between Real Wage Rates and Employment: An Intertemporal General Equilibrium Analysis", German Economic Review 5, 263-295.

Lloyd-Braga, T. and L. Modesto [2007]: "Indeterminacy in a Finance Constrained Unionized Economy", Journal of Mathematical Economics 43, 347-364.

Nash, J. [1950]: “The Bargaining Problem”, Econometrica 18, 155-162.

Rocheteau, G. [1999a]: "Balanced-budget Rules and Indeterminacy of the Equilibrium Unemployment Rate", Oxford Economic Papers 51, 399-409.

Rocheteau, G. [1999b]: "Can an Unemployment Insurance System Generate Multiple Natural Rates?", International Tax and Public Finance 6, 379-387.

Rubinstein, A. [1982]: "Perfect Equilibrium in a Bargaining Model”, Econometrica 50, 97-109.

Skaksen, J.R.[2004]: "International Outsourcing when Labour Markets are Unionized", Canadian Journal of Economics 37, 78-94.

Spector, D. [2004]: "Competition and Capital-Labor Conflict", European Economic Review 48, 25-38.

van der Ploeg, R. [1987]: “Trade Unions, Investment and Unemployment: A Noncooperative Approach”, European Economic Review 31, 1469-1492. 